\title{
Examining predictors of retention with implications for TESTA@Greenwich
}

\author{
Simon Walker, Duncan McKenna, Abdillahi Abdirahman Abdillahi, Catherine \\ Molesworth, University of Greenwich
}

\section{Introduction}

\section{Identifying 'hard to reach' students.}

Engaging so-called 'hard to reach' students remains a core mission of the UK Higher Education widening participation agenda and is the key focus of the REACT project. A conclusive definition of 'hard to reach' has been elusive as the breadth and depth of possible definitions continues to expand. Therefore, for the sake of clarity and rigour, the authors of this paper took a definition of 'hard to reach' at its most extreme form - students who have left the university. This lens allowed us to be certain of our definition and investigate the wider issues of retention at the university whilst also contributing to sector-wide understanding.

There are significant rates of non-continuation between groups of students with different characteristics and these vary from institution to institution. It is therefore valuable for each institution to understand the impact of any interventions that make a difference to supporting all their students to stay on course and achieve their full potential. This work aligns well with the three core aims of the UK's national strategy for access and student success in higher education: improving reduction in the number of students who withdraw early from higher education; narrowing the gap between the retention rates of the most advantaged and most disadvantaged; improving outcomes for different student groups by addressing the unexplained differentials in attainment (BIS, 2014:12).

Through interrogating institutional statistics, we hoped to identify those factors which best predicted a student's likelihood of dropping out and, thereby, those groups most at risk and thus 'hardest to reach'. We chose to investigate many factors, including whether TESTA our (now mandatory) institutional feedback and assessment curriculum enhancement process - was significant in predicting retention. TESTA was included because of its institutional reach and effectiveness in creating change within the University of Greenwich. This research afforded us the potential to apply TESTA in a novel way and explore specific interventions that would tackle the issues our research uncovered.

Research undertaken by the HE Academy and the Equality Challenge Unit on retention and attainment notes the importance of curriculum design and learning, teaching and assessment practice: ensuring that students are fully engaged and active as partners in the learning contract can impact significantly on their engagement and overall experience (Crozier et al, 2008; David 2009; Roberts, 2011; Stevenson, 2012; Thomas, 2012; Burke et al, 2013). Since issues related to the retention of students and to the improving of attainment are multiple and complex, there is no universal panacea for success. However, in the context of now general acceptance that there is real value in early clarification to students of assessment practices and expectations, in keeping them informed about their progress and attainment and in encouraging them to use feedback productively (Thomas, 2012), this paper examines the potential impact of TESTA on 'hard to reach' students.

\section{Intervening to help 'hard to reach' students through TESTA}

The University of Greenwich adopted TESTA, piloting an adapted version in 2013, as part of a commitment to its Quality Enhancement and Quality Assurance process. TESTA now forms one component of the quinquennial Programme Review process, and has so far 
worked with over 140 programmes, helping to enhance the design and implementation of assessment and feedback practice across the institution. This constitutes one of the broadest and most successful adoptions of the TESTA methodology in the sector (Jessop, 2017) and we believe much of this is down to the approach and adaptation of the TESTA methodology, known as TESTA@Greenwich.

\section{Rationale for using TESTA to investigate retention}

TESTA is a comprehensive process which investigates the student experience of feedback and assessment at programme level. It uses qualitative and quantitative data gathered from a wide range of written and verbal sources - those including staff and students - to provide programme teams with a 'bird's-eye view' of assessment. It provides data, analysis and nonbinding recommendations for areas of praise and for improvement. TESTA@Greenwich is used in conjunction with Map My Assessment (MMA), an embedded assessment visualisation tool created at the University of Greenwich (Walker, 2017).

MMA captures course assessment information such as assessment type, weighting, hand-in and feedback dates for each course concurrently within a programme and displays it as a real-time animation, enabling programme teams to spot assessment bunching for students at programme level. This simple visual representation allows staff to 'design out' clashing deadlines and explore whether the assessments are adequately aligned with other courses within a programme, thus enabling students to manage their time better. The tool supports a simple development process that allows staff to play with the assessment components of their courses and see graphically, in real time, the consequences of their design decisions at programme level.

\section{The TESTA@Greenwich methodology}

The TESTA@Greenwich methodology comprises three main elements:

1. Assessment Experience Questionnaire (AEQ). This is a questionnaire which asks students questions about their whole experience of assessment and feedback on their programme, up to the point at which is it administered;

2. Focus Groups. The TESTA@Greenwich focus groups are used to gain qualitative data to add texture and depth to the quantitative data, in order to gain a better understanding of what students are reporting;

3.TESTA@Greenwich Audit. The Audit section of the TESTA process looks at the assessment and feedback environment on the programme in terms of what the programme delivers to students, rather than their opinions on it.

TESTA@Greenwich expanded the approach to include more information about assessment types and the proportional balance between them, the number of group assessments and the number of 'hidden' assessments (those which are not formally recorded or reports) on each programme. It also expanded the audit of feedback beyond an average volume of feedback to include an analysis of the quality and type of feedback. These data are largely collected from the university's student information system in collaboration and communication with the relevant programme team.

These additions to the original methodology enhance the holistic nature of the approach and ensure that a broad range of data is captured, gathering rich stories about student experiences of any given programme. This allows TESTA to draw links between aspects of assessment and feedback and a student's satisfaction on a programme, providing insight 
into their levels of engagement and potentially, retention. This, in conjunction with the aforementioned effect of assessment and feedback on student engagement, made TESTA@Greenwich an attractive basis for our investigation into 'hard to reach' students at the University of Greenwich.

A principal underpinning of TESTA@Greenwich is the ethos of partnership, which is key to fostering positive engagement with the process, and maximising the pedagogic and practical gain, as well as increasing the prospects for continued embedding and resourcing of TESTA across all four faculties. This deep institutional commitment provided a strong platform for TESTA to produce data for the REACT project, but also a jumping-off point for interventions once the findings of the project were analysed. Hence, we chose TESTA@Greenwich as our independent variable for investigating retention and, therefore, our 'hard to reach' groups.

An example of how TESTA findings may have impact upon student experience and retention are provided in Table 1, which lists the most frequently-cited recommendations to programme teams.

\begin{tabular}{|c|c|c|}
\hline Percentage & Category $n=55$ & Recommendation and Reason \\
\hline $54 \%$ & $\begin{array}{l}\text { Assessment } \\
\text { Expectations }\end{array}$ & $\begin{array}{l}\text { Create/use clear marking criteria to ensure students understand } \\
\text { what is required of them to attain certain levels of achievement }\end{array}$ \\
\hline $54 \%$ & $\begin{array}{l}\text { Assessment } \\
\text { Expectations }\end{array}$ & Create/use clear marking criteria to ensure consistency \\
\hline $49 \%$ & $\begin{array}{l}\text { Assessment } \\
\text { Expectations }\end{array}$ & $\begin{array}{l}\text { Provide more clear goals and standards to ensure students are } \\
\text { aware of expectations around assessments }\end{array}$ \\
\hline $49 \%$ & $\begin{array}{l}\text { Assessments } \\
\text { (Timing) }\end{array}$ & $\begin{array}{l}\text { Space assessments differently (MMA) to reduce assessment } \\
\text { bunching }\end{array}$ \\
\hline $47 \%$ & $\begin{array}{l}\text { Assessments } \\
\text { (Number) }\end{array}$ & $\begin{array}{l}\text { Reduce the number of assessments because students are feeling } \\
\text { overwhelmed by the number of assessments }\end{array}$ \\
\hline $38 \%$ & Fairness & $\begin{array}{l}\text { Ensure consistency of programme delivery so that students feel } \\
\text { fairly treated }\end{array}$ \\
\hline $34 \%$ & $\begin{array}{l}\text { Feedback } \\
\text { (Content) }\end{array}$ & $\begin{array}{l}\text { Provide deeper, more balanced feedback to ensure praise, } \\
\text { criticism and advice is present in all feedback }\end{array}$ \\
\hline $27 \%$ & $\begin{array}{l}\text { Feedback } \\
\text { (Timing) }\end{array}$ & $\begin{array}{l}\text { Investigate/address return times of feedback to ensure students } \\
\text { get the most out of their feedback }\end{array}$ \\
\hline $27 \%$ & $\begin{array}{l}\text { Feedback } \\
\text { (Consistency) }\end{array}$ & Ensure feedback is more consistently delivered \\
\hline $23 \%$ & $\begin{array}{l}\text { Feedback } \\
\text { (Content) }\end{array}$ & $\begin{array}{l}\text { Provide deeper, more balanced feedback to ensure praise, } \\
\text { criticism and advice are present in all feedback }\end{array}$ \\
\hline $23 \%$ & $\begin{array}{l}\text { Assessments } \\
\text { (Number) } \\
\text { [Deep Approach] }\end{array}$ & $\begin{array}{l}\text { Reduce the number of assessments because students feel that } \\
\text { too many prevent them from engaging properly with course } \\
\text { material }\end{array}$ \\
\hline $20 \%$ & $\begin{array}{l}\text { Assessments } \\
\text { (number) } \\
\text { [Hidden] }\end{array}$ & $\begin{array}{l}\text { Reduce the number of assessments because there are many } \\
\text { hidden assessments }\end{array}$ \\
\hline
\end{tabular}




\section{Theme 3: Retention and Attainment}

\begin{tabular}{|l|l|l|}
\hline $20 \%$ & $\begin{array}{l}\text { Feedback } \\
\text { (Framing) } \\
\text { [Comms] }\end{array}$ & $\begin{array}{l}\text { Explain feedback to students more clearly to ensure students } \\
\text { understand what constitutes feedback (sign-posting) }\end{array}$ \\
\hline $20 \%$ & $\begin{array}{l}\text { Group Work } \\
\text { (Grading } \\
\text { methods) }\end{array}$ & $\begin{array}{l}\text { Consider assessment systems for group work to alleviate student } \\
\text { concerns over fairness }\end{array}$ \\
\hline
\end{tabular}

Table 1. Most frequently-cited recommendations

\section{TESTA areas potentially affecting retention}

From the data collected through TESTA@Greenwich, themes emerged as to the key areas that could have impact upon retention for certain groups of students. Discussed below are the main five areas:

Clarity of goals and standards - Throughout the TESTA process, the clarity of information provided to students relating to their assessments has been a key issue for student satisfaction and engagement. Students who are unclear about what is expected of them when submitting assignments report elevated levels of stress, confusion and disillusionment, all of which can be further compounded by receipt of feedback or return of their work, if assessment results do not meet their expectations. If this occurs repeatedly, students can become discouraged and disengaged, as seen from students' quotes in focus groups:

"If all courses were laid out how they were in the handbook and the assessment were what they said, it would have been a much easier way to learn, and not as stressful for us."

Assessments - Students interviewed through TESTA report that the number and timing of assessments have a significant effect on their ability to engage with learning material, attend classes, complete assessments to their satisfaction or engage in formative assessments and deep learning; their levels of stress rise accordingly. These factors can have an impact on student retention.

"I always find the first term a bit of a guessing game - you don't know if you're doing great, or really bad, because all the assessments are at Christmas; so you might be going through a 12 week term, without knowing anything, so you could be doing four or five pieces of coursework and you've got no feedback for any of it, and then you get a bunch of low [graded] assessments, and that's all at one time."

Feedback - Data collected during the TESTA process suggests that, if feedback is not improvement-focused, students' satisfaction and engagement with their programme may be adversely affected. Students who do not believe they are being helped to improve and strive towards their goal of high-level performance report feelings ranging from anger, to not getting 'value for money':

“...you should be getting your money's worth because you come to uni to do something that you're interested in, not to get the passion sucked out of you because [staff] aren't doing what they're supposed to be doing."

Deep Approach - Some students indicate a sense of disenchantment with 'working towards the test', as they believed university would offer them a chance to explore topics in greater depth: 
"You can't do everything well, if you have 10 things to do you can't focus on everything, there's a lot of pressure and a student cannot enjoy their learning."

Communication - Poor staff communication and disengagement can leave students feeling isolated, especially when they are struggling academically, leading to disengagement and unhappiness:

"There was one lecturer we kept emailing because we wanted feedback and we got one email, the whole group, saying, please leave me alone, l'm trying to do my work."

Fairness - Students who reported feeling that their work was unfairly marked, or that submission practices were unfair, were left feeling angry and powerless. They also struggled when inconsistent guidance was given by different members of a course team, leaving students feeling lost and unsure how to proceed with assessments.

"...some people got their grades back before the exam which is really good for them because they can reflect on them...but I still haven't got my grade and it's a week after the exam... I could have really benefited from [that]."

We calculated from comments such as these that, even if the use of TESTA@Greenwich as a variable in a large-scale data analysis was not found to be an effective factor for retention, it could still form part of a strategy to tackle areas which were, given its deep embedding and direct access to programme teams within an enhancement framework. To examine the statistical significance, we therefore conducted a large-scale data analysis exercise.

\section{Methodology}

The initial dataset comprised 28,824 student records and was compiled from a subset of three statutory submissions to the Higher Education Statistics Agency (HESA). HESA is the official body for processing quantitative data about higher education in the UK, somewhat similar in function to the Integrated Postsecondary Data System (IPEDS) in the US. The HESA submissions showed the University of Greenwich student population on $31^{\text {st }}$ October at the end of academic sessions 2013/14, 2014/15, and 2015/16. Students were undergraduates on three-year courses, including three years of integrated undergraduate/postgraduate-taught masters degrees (Hesa field M22). Students were all full-time, on-campus and eligible for Home fees. This population excluded early withdrawals (students who fully registered and withdrew before $1^{\text {st }}$ December in the year of entry).

One of the statistical assumptions of the planned analysis, logistic regression, is that observations are independent. In practice, this means that each student can contribute their data only once to the analysis (i.e. there can be no repeated measures' predictors). For this reason, students were separated into year of programme (Year 1, 2, or 3) and students who were 'lagging' at the start of the year of programme were excluded from the dataset for that year of programme - a student was defined as 'lagging', if the date on which they started their course fell outside the expected academic session. For example, if a student was in the second year of a programme in academic session 2014/15, but the date on which the student started the course fell outside the academic session August 2013 to July 2014, that student was counted as lagging for that year of programme. Removal of lagging students left a total of 10,156 first-year students, 7585 second-year students and 7072 third-year students.

The outcome variable in the analysis was retention. Students were defined as 'retained' if their progression path submitted to HESA was not 'fail and leave' or 'withdrawn'. All other students were defined as 'dropped out'. The number of dropped-out students decreased 
exponentially across year of programme. In Year One, 671 students (2.7\%) dropped out; in Year Two, 86 students $(<0.3 \%)$ dropped out and fewer than 10 students $(<0.04 \%)$ dropped out in Year Three. We proceeded to analyse data from students from Year 1 only, because the outcome variable had the greatest variability for that year of programme. Thus, our final sample with which our analyses was conducted consisted of 10,156, 'non-lagging', first-year students.

\section{Model}

We used binary logistic regression because the outcome variable, retention, is dichotomous ('retained' vs 'dropped-out'). In addition, a regression allowed us to carry out a pre- and posttest on the effect of TESTA on retention, whilst controlling for any major changes in retention over the same time period in programmes without TESTA implementation (i.e. Non-TESTA programmes).

Students within our sample were therefore either classified as being retained or as dropping out. Owing to the binary nature of the outcome variable, coupled with the fact that logistic regression does not assume a linear relationship between the dependent and independent variables, logistic regression was found to be appropriate for this study.

The 10 independent variables (the number of sub-categories of each predictor displayed here in parentheses) were:

1. Ethnicity (13)

2. POLAR (6)

3. Age Group (4)

4. Gender (2)

5. Highest Qualification on Entry (HQOE) (8)

6. Jacs (15)

7. $\quad$ Last Institution (16)

8. Socioeconomic Status (8)

9. TESTA (3)

10. Academic Session (3)

\section{TESTA@Greenwich}

The two predictors, TESTA and Academic Session, allowed us to look at the effect of TESTA on retention. TESTA (using levels TESTA Round 1, TESTA Round 2, and No TESTA) divided programmes according to whether they implemented TESTA recommendations in Round 1, Round 2, or whether programmes did not go through TESTA at all. It is important to note that programmes in both rounds of TESTA are mutually exclusive of one another. The interactions allowed us to compare the odds of retention for programmes that implemented TESTA in a particular academic session, with the odds of retention for those same programmes pre-TESTA, in the immediately preceding academic session. This comparison was made relative to any changes in the odds of retention across the same academic sessions, in programmes that received no TESTA at all.

A breakdown of the levels of TESTA is given in Table 2 below. $\mathrm{N}$ represents the total number of TESTA subjects within our sample, over the three academic sessions (13/14, 14/15 and 15/16), and Programmes represents the number of programmes that went though/did not go through TESTA.

\begin{tabular}{|c|l|l|l|}
\hline \multicolumn{1}{|c|}{ Predictor } & \multicolumn{3}{|c|}{ TESTA } \\
\hline Sub-category & Round 1 & Round 2 & No TESTA \\
\hline Year of Implementation & $14 / 15$ & $15 / 16$ & N/A \\
\hline
\end{tabular}


Theme 3: Retention and Attainment

\begin{tabular}{|c|l|l|l|}
\hline $\mathbf{N}$ & 249 & 215 & 9692 \\
\hline Programmes & 3 & 3 & 227 \\
\hline
\end{tabular}

Table 2. TESTA Predictor by total number of students and programmes

We also added an interaction term 'TESTA by Academic Session' and made 'No TESTA' and the middle session, ' $14 / 15$ ', the reference categories for these predictors.

The interactions allowed us to compare the odds of retention for programmes that implemented TESTA in a particular academic session, with the odds of retention for those same programmes, pre-TESTA, in the immediately preceding academic session. This comparison was made relative to any changes in the odds of retention across the same academic sessions, in programmes that received no TESTA at all.

This design enabled us to test specific predictions: If TESTA Round 1 significantly increased retention, we expected to find a significant Session (13/14) by TESTA Round 1 interaction. This was because TESTA Round 1 was implemented in TESTA Round 1 programmes in the academic session 14/15 (the reference category), but not academic session 13/14. If TESTA Round 2 significantly increased retention, we expected to find a significant Session (15/16) by TESTA Round 2 interaction. This was because TESTA Round 2 was implemented in TESTA Round 2 programmes only in academic session 15/16, but not in the reference category, academic session 14/15. More detail about the other predictors, are provided in the supplementary file.

Prior to running the regression, mergers/groupings of several sub-categories were done to ensure that each level of our predictors had ten or more events, the minimum number needed for reliable parameter estimates (Peduzzi et al, 1996). We define events here as the number of retained students per level. The merges were as follows: Under the 'Last Institution' predictor, 'Agriculture and Horticultural College', as well as 'Language Schools' were merged together with the Unknown sub-category, as they were too small to be analysed separately. For the predictor 'Jacs Grouping', the subject group 'Broad-based Programmes with Languages' was merged together with the 'Languages' subject group to create an encompassing 'Languages' sub-category. For 'Highest Qualification on Entry', 'Other Qualifications' was merged with the 'None' sub-category to form 'Other Qualifications and None'. Lastly, for the 'Age Group' predictor, 'Under 18' and '18-20' age groups were merged to create 'Under 21 '.

\section{Results}

\section{Model Fit and Prediction:}

Goodness of fit of a statistical model refers to how accurately the model describes the data set; specifically, how well expected values under the model match the observed values. The model presented here had good model fit as shown by a non-significant Hosmer and Lemeshow Chi-square test. This suggests that the choice of statistical model was appropriate for the data.

Predictive power describes how well the model uses the data to predict the outcome variable. One metric that measures predictive power for logistic regression, is the Nagelkerke $R^{2}$ which ranges from 0 (no predictive power) to a maximum of 1 . Predictive power was weak for this analysis, as indicated by a low Nagelkerke $R^{2}$ (see Table 3 below). This may suggest that we captured only a subset of important predictors of retention in this analysis and that additional predictors are needed to gain better predictive power. 
Theme 3: Retention and Attainment

\begin{tabular}{|l|l|c|c|c|}
\hline $\begin{array}{l}\text { Analysis Outcome } \\
\text { Variable }\end{array}$ & $\begin{array}{l}\text { Hosmer and } \\
\text { Lemeshow Chi- } \\
\text { Square }\end{array}$ & df & P value & ${\text { Nagelkerke } \mathbf{R}^{2}}^{\mathbf{2}}$ \\
\hline 1. Retention vs. Drop-out & 12.894 & 8 & .116 & .055 \\
\hline
\end{tabular}

Table 3. Statistical test of model fit and prediction

The remainder of this section describes the findings and results of the analysis. Table 4 presents results for the interaction term 'TESTA x Academic Session', while Table 5 only presents the regression results of only predictors (and their sub-categories) that reported $p$ values of $<.05$. For both tables, the reference categories are in bold. All results are presented in terms of 'odds ratios'. An odds ratio is the odds of one group of students (e.g. students with BTECs) achieving an outcome (in this case being retained) divided by the odds of another group of students, who form a reference group (e.g. students with A-levels) achieving the same outcome. If the odds ratio between these two groups in this example was, for example:

$=1$, then both groups have the same odds/probability of being retained;

$>1$, then students with BTEC's would have higher odds/probability of being retained students with A-levels;

$<1$, then students with BTEC's would have lower odds/probability of being retained than students with A-levels.

It is important to note that the comparisons are always made in relation to the reference category, hence why in the example above, BTEC students were always compared against A-level students (which was our reference group). The interpretation can be reciprocated by changing the reference category. With this understanding of odds ratios, our key findings are summarised as follows:

\section{Part 1:}

The odds of completion for students with Black African ethnicity were just a proportion (0.7) of White students (this relationship was highly statistically significant at the $1 \%$ level). This meant that for every 100 'White' students that the university retained, 70 'Black' students were retained. Mixed ethnicities had an almost identical chance of being retained to Black Africans (0.71) when compared with White students; however, the statistical significance of Mixed ethnicities was less robust at the $5 \%$ significance level. Both Chinese and Indian ethnicities had better odds of being retained than White students; however, both these ethnicities reported $p$-values of $10 \%$, which was above our significance threshold of $5 \%$.

Regarding Age Groups, all but the 25-29 sub-category showed statistically significant effects on retention at the 5\% level. Students aged between 21-24 years old were the only age groups to have worse odds of being retained (0.79) when compared with the reference category Under 21's. More mature students however, seemed to have better odds of retention. For instance, students ' 30 and over' had 1.56 the odds of Under 21's at being retained.

With regard to Highest Qualification on Entry, the odds of retention by students with BTEC as their highest qualification is a smaller proportion, .54 of the odds of retention by students with A Levels, Highers and Equivalent. The regression also revealed that students holding postgraduate degrees studying for another undergraduate degree were also far less likely to be retained, with 0.204 of the odds of students holding A-levels. Both relationships were highly statistically significant at the $1 \%$ level.

Gender was also a highly important predictor of retention, with women having 1.38 greater odds of being retained than men (statistically significant at the $1 \%$ level). 
Lastly, Academic Session, with years 2013/14 and 2014/15 both having better odds of retention (1.36 and 1.46 respectively) to year $2015 / 16$ (statistically significant at the $1 \%$ level).

\section{Part 2:}

As mentioned above, an interaction between TESTA and Academic Session was also included as a predictor in the regression. This interaction, however, was found to be statistically insignificant across all academic sessions, indicating that TESTA was not an important predictor as far as retention is concerned.

\begin{tabular}{|c|c|c|c|c|}
\hline \multirow[t]{2}{*}{ Independent variable } & \multirow[t]{2}{*}{ Significance } & \multirow{2}{*}{$\begin{array}{l}\text { Odds } \\
\text { ratio }\end{array}$} & \multicolumn{2}{|c|}{$95 \% \mathrm{Cl}$} \\
\hline & & & Lower & Upper \\
\hline $\begin{array}{l}\text { TESTA*Academic Session } \\
(p=.472)\end{array}$ & & & & \\
\hline No TESTA * $2014 / 15$ & & 1 & & \\
\hline TESTA Round 1 * 2013/14 & 0.206 & 0.491 & 0.163 & 1.480 \\
\hline TESTA Round $1^{*}$ 2015/16 & 0.252 & 0.433 & 0.103 & 1.812 \\
\hline TESTA Round 2* 2013/14 & 0.698 & 0.808 & 0.274 & 2.377 \\
\hline TESTA Round 2* 2015/16 & 0.801 & 0.832 & 0.201 & 3.456 \\
\hline
\end{tabular}

Table 4. Interaction between TESTA and Academic Session

\begin{tabular}{|c|c|c|c|c|c|}
\hline \multirow[t]{2}{*}{ Independent variable } & \multirow[t]{2}{*}{$\mathbf{N}$} & \multirow[t]{2}{*}{ Significance } & \multirow{2}{*}{$\begin{array}{l}\text { Odds } \\
\text { ratio }\end{array}$} & \multicolumn{2}{|c|}{$95 \% \mathrm{Cl}$} \\
\hline & & & & Lower & Upper \\
\hline \multicolumn{6}{|l|}{ Ethnicity $(\mathrm{p}=.033)$} \\
\hline White & 5613 & & 1 & & \\
\hline Black African & 1201 & 0.008 & 0.700 & 0.538 & 0.912 \\
\hline Mixed & 551 & 0.046 & 0.715 & 0.514 & 0.994 \\
\hline \multicolumn{6}{|l|}{ Age Group ( $p=.007)$} \\
\hline Under 21 & 7230 & & 1 & & \\
\hline $21-24$ & 1341 & 0.045 & 0.788 & 0.624 & 0.994 \\
\hline $30+$ & 1029 & 0.032 & 1.566 & 1.039 & 2.360 \\
\hline \multicolumn{6}{|l|}{ Gender $(p<.001)$} \\
\hline Male & 4171 & & 1 & & \\
\hline Female & 5985 & $<0.001$ & 1.378 & 1.155 & 1.644 \\
\hline \multicolumn{6}{|l|}{$\begin{array}{l}\text { Highest Qualification on } \\
\text { Entry }(p<.001)\end{array}$} \\
\hline $\begin{array}{l}\text { A Levels, Highers \& } \\
\text { Equivalent }\end{array}$ & 2676 & & 1 & & \\
\hline $\begin{array}{l}\text { Postgraduates (studying for } \\
\text { another undergraduate } \\
\text { degree) }\end{array}$ & 32 & 0.006 & 0.204 & 0.065 & 0.638 \\
\hline BTEC & 1788 & 0.000 & 0.542 & 0.420 & 0.699 \\
\hline \multicolumn{6}{|l|}{ Academic Session $(p=.007)$} \\
\hline $2015 / 16$ & & & 1 & & \\
\hline $2013 / 14$ & 3458 & 0.013 & 1.363 & 1.068 & 1.740 \\
\hline $2014 / 15$ & 3404 & 0.005 & 1.430 & 1.117 & 1.831 \\
\hline
\end{tabular}

Table 5. Significant predictors of retention 


\section{Limitations.}

There were several limitations to the study which are outlined below:

Although TESTA has been running since March 2014, there is a limit to existing data sets surrounding retention. The overlap with these data and TESTA data was limited to the period which covered the pilot and first iteration of TESTA@Greenwich in 2014-15, where the methodology was being honed and fewer programmes were involved. With the third iteration in 2015, TESTA@Greenwich became a mandatory process in two faculties, and only expanded to other 2 faculties for the fourth iteration in 2016; therefore it was not possible to create a picture across the whole institution.

\section{Discussion}

Student retention could be reduced to a binary discussion: students who stay and students who leave. Although a contested and as yet undefined term, the REACT projects sought to investigate how to increase retention rates by exploring who 'hard to reach' student groups might be. These may be defined by a broad range of characteristics, but differ from provider to provider and are, to some extent, the result of idiosyncrasies and local context. What may be defined as 'hard to reach' for one provider may be different from another. Although TESTA was not a significant factor in predicting retention (our baseline definition of 'hard to reach'), our research comparing TESTA programmes has allowed us to see what is.

Emerging from our data analysis is a clear picture of groups of students who leave the University of Greenwich before the completion of their degree programme at a significantly higher rate than that of their peers. In the absence of any commonly-agreed definition of 'hard to reach', we propose that the following groups form our definition of 'hard to reach' students for this paper, and for the University of Greenwich student population:

- First-year students

- Students with BTECs and students with postgraduate qualifications studying for another undergraduate degree

- Black African students and those of mixed heritage

- Somewhat older students ('21-24s')

- Male students

Having investigated retention rates at the University of Greenwich in relation to TESTA as well as the above range of other factors, we can now say that no statistically significant relationship has been discovered between the TESTA pilot and first round of TESTA@Greenwich implementation with retention of students at the University of Greenwich in this study.

However, these results do have implications for TESTA@Greenwich and there is potential to have impact upon students at risk of leaving. The over-riding principle is to adopt a "design for all' approach where changes that are made to improve conditions for a small minority benefit everyone. Small changes to the design of TESTA@Greenwich can reap large benefits for those 'hard to reach' groups and other students. TESTA operates at a macro level (programme rather than course/module level), so it can be used over the mid- to longterm to stimulate change at programme/department and faculty level, thereby potentially with impact across the whole university. Out of many curriculum interventions, it is an appropriate tool to tackle some basic challenges that may be experienced for all students, including those defined as 'hard to reach'. From this, we can determine various ways in which TESTA @Greenwich can be further developed or utilised. A series of these potential developments is discussed below.

1. Currently, programme teams have access to an increasing amount of data about their students. The university collates data from very large datasets. Using a novel 
visualisation approach (viewed through Tableau Reader), it provides a dashboard that enables programme teams to compare, evaluate and monitor programme performance from year to year. This includes detailed views of entry qualifications, ethnic composition, gender, age, etc. However, there is a risk of 'data overload' or misinterpretation, especially for programme leaders who may be new to the job. TESTA can provide a useful frame of reference for contextualising this data dashboard through the everyday, lived experience programme team members have with feedback and assessment. TESTA can provide reliable pointers for specific interventions - for example, clarifying goals and standards throughout an undergraduate's first year, whether at risk or not.

2. TESTA is now required as part of the Periodic Review process for all programmes at the University of Greenwich, but, as this process moves toward a more collaborative, enhancement-based approach, and every programme has been through TESTA at least once, it is possible TESTA@Greenwich could become more risk-based, where acknowledging the presence of large groups of 'hard to reach' students is considered as a factor in these risk calculations. This would have the benefit of diverting TESTA resources to where they are most needed.

3. As more and more programmes undertake TESTA and MMA analysis, we can continue to overlay TESTA data with retention data to see which areas either display concurrent issues or find resolution. Where issues persist, these can be investigated further as part of the Review Research process to discover links and come up with potential solutions at local level.

4. Currently, student focus groups comprise students who have experienced programme assessment and feedback and are in the best place to comment on improvements. Given that first-year undergraduates are by far the most at risk and 'hard to reach', efforts should be now made to engage them specifically following their first assessment rounds. There may be considerable gain in engaging these students, albeit with less experience of assessment and feedback, by developing a programme strategy aimed at retention, to target support for first years.

5. Recommendations stemming from TESTA analysis can be targeted specifically at Level 4. This would include splitting out first-year results from the AEQ and showing the programme team how the first year compares with other years. This would encourage teams to focus on particular years and how issues related to Assessment and Feedback may be affecting students.

6. A range of curriculum design workshops can be deployed by programme teams to address issues and challenges, post TESTA. These can include techniques such as 'Viewpoints' (Masson, 2012) or Snakes and Ladders (Killen, 2016).

7. A new cycle for Review and Approval that is enhancement focused is currently being developed. This will require programme teams to engage with TESTA earlier than before, and will capture issues at an earlier stage. This will be particularly important for newly-approved programmes and reduce the risk of students' being exposed to ineffective curriculum design.

\section{Conclusion}

The results of our analysis revealed that of the ten predictors selected, the following were statistically significant in predicting those at risk of dropping out of the university: age group; gender; ethnicity; highest qualification on entry and academic session. These form the basis 
of our definition of who are 'hard to reach' students are. Although we identified as many as five statistically significant predictors of retention, the low predictive power of our model suggests that we would need many additional variables to increase substantially predictive ability. Student retention is a complex, multi-faceted phenomenon and multiple predictor variables are needed to build a comprehensive model of student retention.

For the limited dataset available, TESTA was not shown to be an important predictor for retention. However, we have established an approach for using an effective evidence-based methodology that provides a rigorous test for TESTA that can be applied to 'hard to reach' with a larger sample size. Furthermore, whilst TESTA had no statistically significant impact on retention during the pilot and first iteration, several important implications for the design of TESTA@Greenwich in relation to assessment design and delivery for 'hard to reach' groups have emerged. This paper therefore, identifies a plan for the future implementation of TESTA which we believe has potential to improve retention across the university and to reach out to those students who are 'hard to reach'.

\section{Acknowledgments}

The authors are grateful to members of the Planning and Statistics Department for their advice on data collection and analysis - Christine Couper, Myles Houghton, Chi Le, and Debbie Grossman.

\section{Reference list}

ARC Network (2013) Literature review of research into widening participation to higher education. Available at:

http://www.hefce.ac.uk/media/hefce/content/pubs/indirreports/2013/Literature,review, of,WP,t o,HE/Literature\%20review\%20of\%20research\%20into\%20WP\%20to\%20HE.doc (Accessed : 22 May 2017).

BIS (2014) National strategy for access and student success in higher education. Available at:

https://www.gov.uk/government/uploads/system/uploads/attachment data/file/299689/bis14-516-national-strategy-for-access-and-student-success.pdf (Accessed : 22 May 2017).

Burke, P., Crozier, G., Read, B., Hall, J., Peat, J. and Francis, B. (2013) Formations of gender and Higher Education Pedagogies. NTFS Final Report.

Crozier, G. Reay, D. Clayton, J. and Colliander, L. (2008) 'Different Strokes for Different Folks: Diverse Students in Diverse Institutions - Experiences of Higher Education.' Research Papers in Education, 23(2), 167-177.

David, M (2009) Widening Participation Through Improving Learning. London and New York: Routledge.

Department for Education (2016) Teaching Excellence Framework: year two and beyond. Available at:

https://www.gov.uk/government/uploads/system/uploads/attachment data/file/557140/Teach ing Excellence Framework - Technical Con Response.pdf (Accessed : 22 May 2017).

Jessop, T. (2017) Fostering Educational Change through research: Stories from the field. Southampton Solent University. Available at: https://www.solent.ac.uk/events/2017/fosteringeducational-change-through-research-stories-from-the-field (Accessed : 22 May 2017). 
Killen, C., Walker, S (2016) 'What will a successful student-staff partnership look like in 2020 and how should we measure impact?' Raise 2016. Available at: http://www.raisenetwork.com/events/past-conference-archive/ (Accessed : 22 May 2017).

Masson, A (2012) Viewpoints. Available at: http://wiki.ulster.ac.uk/display/VPR/Home (Accessed : 22nd May 2017).

Peduzzi, P., Concato, J., Kemper, E, Holdford, T. and Feinstein, A. (1996) 'A simulation study of the number of events per variable in logistic regression analysis.' Journal of Clinical Epidemiology, 49(12) 1373-1379.

Roberts, S. (2011) 'Traditional practice for non-traditional students? Examining the role of pedagogy in higher education retention.' Journal of Further and Higher Education, 35(2), 183-199.

Stevenson, J. (2012) Black and minority ethnic student degree retention and attainment. York: Higher Education Academy. Available at:

http://www.heacademy.ac.uk/assets/documents/retention/Summit/bme summit final report. pdf_(Accessed : 22 May 2017).

Thomas, L. (2012) Building student engagement and belonging in higher education at a time of change: final report from the What Works? Student Retention \& Success programme. London: Paul Hamlyn Foundation.

Walker, S (2017) Map my Assessment. London: University of Greenwich. Available at: http://www.mapmyassessment.org/ (Accessed : 22 May 2017). 